\title{
Connecting Geodata Initiatives to Contribute to a European Spatial Data Infrastructure - The CRISOLA Case for Malta and the Project Plan4all
}

\author{
Saviour Formosa ${ }^{1}$, Vincent Magri ${ }^{2}$, Julia Neuschmid $^{3}$, and Manfred Schrenk ${ }^{3}$ \\ ${ }^{1}$ Institute of Criminology, University of Malta, Rm113, Humanities A (Laws, Theology, \\ Criminology), Msida MSD 2080 \\ saviour. formosa@um. edu.mt \\ ${ }^{2}$ Fondazzjoni Temi Zammit, Ir-Razzett tal-Hursun, University of Malta, Msida MSD 2080 \\ vincentaascendconsulting.eu \\ ${ }^{3}$ CEIT Alanova, Central European Institute of Technology, Institute of Urbanism, Transport, \\ Environment and Information Society, Concorde Business Park 2/F, \\ 2320 Schwechat, Austria \\ j.neuschmid@ceit.at, m.schrenk@ceit.at
}

\begin{abstract}
The Malta CRISOLA case study is investigated in terms of its analysis of the approaches taken to ensure that data in the physical and social domains are tackled within a reliable structure as that provided by the spatial domain through INSPIRE. The crime, social and landuse themes, being pivotal to the model, have served as a bridge across the landuse domains identified as fundamental in the INSPIRE Directive and as expressed in the Plan4all project. The case study is described in terms of its eventual take-up of functions developed by the Plan4all project which are essential for the future successful outcomes as identified in the CRISOLA model. The idea is to disseminate Maltese results to other geoportals including Plan4all geoserver which focuses on the interoperability and harmonisation of spatial planning data. The aims are to support holistic planning through the provision of data services across the spatial and social themes.
\end{abstract}

Keywords: CRISOLA, crime, social data, data interoperability, INSPIRE, crime mapping, mapserver.

\section{Spatial Themes for a Social Science}

\subsection{The Case for Crime and Space: The Urban Ecology Approach}

Why analyse crime as a spatial theme? Crime is an ideal scenario to integrate in a spatial construct as it is a multi-faceted domain encompassing the physical location (offender and offence), the spatial relationships between the offender and victim and the social thematic constructs as they evolve in physical space. The theory of urban ecology or environmental criminology grew from the work of the Chicago School of Sociology, with the main proponents being Shaw and McKay [1] and their 1930s' theory of social disorganisation, which was based on the concept of human urban 
ecology ${ }^{1}[2]$. Urban ecology posits that there is a positive correlation between crime, social issues and landuse [3]. The Malta socio-physico-crime CRISOLA research [4] [5] based its study on this theoretical base as such studies emphasise the vitality of social landscapes and how they impinge on or are impacted by the physical landscapes. The conceptual model is based on the investigation of the correlations between the CRIme, SOcial and Landuse themes, herein embedded as the acronym CRISOLA.

Analysis of the social interactionism in an area enables successful implementation of crime preventive strategies [6] [7]. The study also basis its analysis on Opportunity Theory which studies the way urban structures and landscapes offer opportunities for crime [8] and Routine Activities Theory which postulates that each offender and victim follow repeatable paths or routines that are delineated by the space they live in over time [9].

One particular organisation, the MAPS ${ }^{2}$ programme (previously called the Crime Mapping Analysis Program $\left(\mathrm{CMAP}^{3}\right)$ ) based its approach on the above and even splits its activities around 4 functions: 'i) investigative or crime series analysis, ii) operations research or resource allocation studies, iii) applied research/problem solving, and iv) discrete site analysis such as schools' [10].

\subsection{Spatial Analysis and Its Impact on Social Research: The Criminological Approach}

Crime analysis takes up different forms, from physical pin charting to use of textual documentation to use of tabular data and eventually to the use of crime statistical tools and GIS, aided by value-added modules that cater specifically for crime. As detailed above, access to data is still a major issue, with access to sensitive crime-related data even more so. The recent online crimemap published by the UK police (http://www.police.uk/) and that available on Malta since 2007 (www.crimemalta.com) show pointdata and aggregated data respectively, whilst the Table 1 depicts three earlier sites that had attempted to publish online crimemaps.

Social-scientific research to date has depended on textual and tabular data that is rarely analysed in a spatio-temporal setting. The use of spatial and temporal analysis of crime data has enabled analysts to combine different resources stored in various formats into a coherent system. With GIS technology, analyses that were not possible in the traditional sense can be identified due to 'its ability to compare multiple geographic factors and investigate geographic correlations' and identify the root cause of a problem [11]. It also has the ability to unravel a complex issue that may be too difficult to investigate using conventional or paper-based methods. GIS aids researchers to generate new knowledge through the use of cross-data analysis such as land zoning and offence location through the concept of layering. Better still, this analysis can be carried out in a time-series process to create a spatio-temporal output, effectively identifying trends and helping to recommend policy change.

\footnotetext{
${ }^{1}$ Also called the 'ecology of crime' due to the relationship between crime and the urban environment.

${ }^{2}$ http://www.ojp.usdoj.gov/nij/maps/

${ }^{3} \mathrm{http}: / /$ www.justnet.org/Pages/Topic.aspx?opentopic=59\&topic=59
} 
Table 1. Published online crimemaps

\begin{tabular}{|c|c|c|c|c|c|c|c|c|}
\hline \multirow[b]{2}{*}{ है } & \multirow[t]{2}{*}{$\begin{array}{l}\text { Site } \\
\text { Name }\end{array}$} & \multicolumn{4}{|c|}{ Web-GIS Level } & \multirow[t]{2}{*}{$\begin{array}{l}\text { Address } \\
\text { nats }\end{array}$} & \multirow[t]{2}{*}{ Comments } & \multirow[t]{2}{*}{$\overline{\text { Limitations }}$} \\
\hline & & 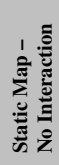 & 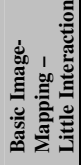 & 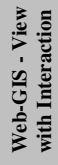 & 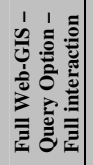 & & & \\
\hline$\overline{\mathrm{EU}}$ & $\begin{array}{l}\text { European } \\
\text { Commissi } \\
\text { on Crime } \\
\text { Map }\end{array}$ & & & & & $\begin{array}{l}\text { http://www.coe.int/ } \\
\mathrm{T} / \mathrm{E} / \text { Com/Files/The } \\
\text { mes/Organised- } \\
\text { crime/map.asp }\end{array}$ & $\begin{array}{ll}\begin{array}{l}\text { Published } \\
\text { map }\end{array} & \text { GIS } \\
\end{array}$ & No interaction \\
\hline$\overline{\mathrm{EU}}$ & $\begin{array}{l}\text { European } \\
\text { Regional } \\
\text { Crime } \\
\text { Database }\end{array}$ & & & & & $\begin{array}{l}\text { http://www.tu- } \\
\text { darmstadt.de/fb/fb1 } \\
\text { /vwl2/deutsch/inhal } \\
\text { te/forschung/eucri } \\
\text { medata.html }\end{array}$ & $\begin{array}{l}\text { Imagemaps based } \\
\text { on what is } \\
\text { essentially a } \\
\text { database }\end{array}$ & $\begin{array}{l}\text { Database is highly } \\
\text { useful, maps are for } \\
\text { visualisation } \\
\text { purposes only - no } \\
\text { interaction }\end{array}$ \\
\hline $\mathrm{EU}$ & $\begin{array}{l}\text { Misdaadk } \\
\text { aart.nl - } \\
\text { Dutch } \\
\text { Crime } \\
\text { Map }\end{array}$ & & & & & $\begin{array}{l}\text { http://www.misdaa } \\
\text { dkaart.nl/ }\end{array}$ & $\begin{array}{ll}\text { Uses } & \text { Google } \\
\text { Maps } & \end{array}$ & In Dutch \\
\hline
\end{tabular}

Source: Formosa (2007, Page 89)

Further developments in the area of crime mapping show an increased application use by police departments and crime analysts, with interest in crimes by such major entities as the Home Office ${ }^{45}$ (UK) and the National Institute of Justice in the US ${ }^{6}$, Interpol $^{7}$, Europol ${ }^{8}$, University of Sheffield ${ }^{9}$, University of Huddersfield ${ }^{10}$, Jill Dando Institute $^{11}$, the University of Liverpool ${ }^{12}$ and the University of Malta ${ }^{13}$.

\subsection{The CRISOLA Model}

A conceptual model was created by Formosa [4] to enable an understanding of the complex Maltese data availability situation together with the spatial requirements for data within the different landscapes that are posited by the crime, social and urban worlds. The study highlighted the need to bring together each aspect and built a mindmap that helps set out a process to depict a basic and generic model on how crime, social and landuse issues interact together, which process also identified techniques and datasets that could be used in the identification and understanding of crime.

\footnotetext{
${ }^{4}$ http://www.homeoffice.gov.uk/

${ }^{5} \mathrm{http} / / /$ www.crimereduction.gov.uk/technology01.htm

${ }^{6} \mathrm{http} / / /$ www.ojp.usdoj.gov/

${ }^{7} \mathrm{http}: / / \mathrm{www}$. interpol.int/

${ }^{8} \mathrm{http}: / /$ www.europol.eu.int/

${ }^{9} \mathrm{http}: / / \mathrm{ccr}$.group.shef.ac.uk/

${ }^{10} \mathrm{http}: / /$ www.hud.ac.uk/hhs/dbs/acc/

${ }^{11} \mathrm{http} / / / \mathrm{www} . j d i . u c l . a c . u k / i n d e x . p h p$

${ }^{12} \mathrm{http} / / / \mathrm{www}$. liv.ac.uk/ecru/

${ }^{13} \mathrm{http}: / /$ www.um.edu.mt/criminology/
} 
The CRISOLA model outlines criminal activity within the social and physical structures it operates in through:

- the crime characteristics through an analysis of offender and offence composition and the interactivity between them [8];

- the social characteristics of an area through an analysis of its poverty/deprivation [12];

- the physical characteristics of an area, particularly its land use, structural and zoning parameters [9].

Whilst, the high-level Phase 1 Model enables a generic focus on the study in question, a more detailed second level model was required which helped point at and identify the interactivity between the three parameters. This is accomplished preferably through the identification of datasets that may be used for analysis. Being a mindmap model, Phase 2 sought to identify those literature-related issues and integrate them within the model. It reviewed the different Theories, Datasets, SpatioTemporal Aspects, predictors and the main tenets that can be used in such a study on

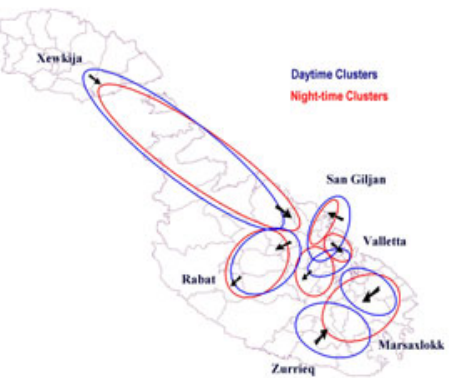

a)

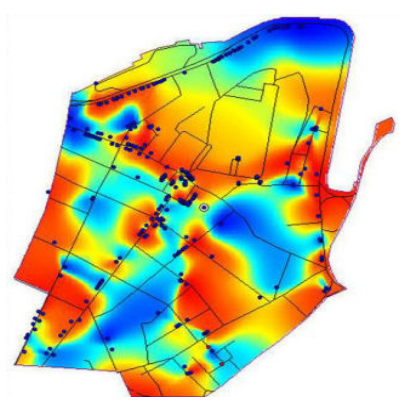

c)

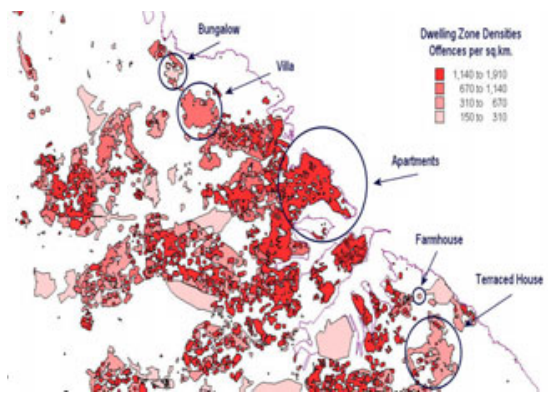

b)

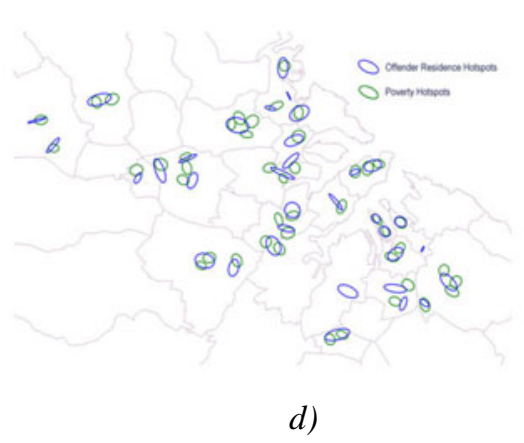

Fig. 1. Spatial outputs from the CRISOLA model research $(a)$ K-Means clustering by day-night periods $(b)$ Offence Densities by Dwelling Type $(c)$ NNH Offence Hotspots $(d)$ NNH1 Poverty (social) ellipsoids and Offender residence 
crime. Taking the model one step further to Level 3, a series of statistical measures are listed for the variables within each dataset identified for model integration The model does not attempt to solve all CRISOLA issues but depicts the potential future studies that can be attempted. The following Figures 1a-d depict outputs from the CRISOLA model research based in Malta.

\subsection{The Tools}

The tools used in this study include CrimeStat, SPSS, MapInfo (Hotspot Mapping Extension), and Vertical Mapper. Methods and statistics included; spatial distribution, distance statistics, 'Hot spot' analysis routines and Interpolation statistics, particularly Moran's I, hot spot, NNA interpolation. Note that each of these methods necessitates knowledge of the limitations in using that specific method which limitations are dependent on a number of factors. These include the sample size taken, the number of minimal points set as the threshold for identifying the least hotspot size, amongst others. In addition, NNH as well-as K-Means employed in the study show their results through ellipsoids, which in effect can cover areas that may not be prone to high incidences being investigated but still fall within the ellipsoid since such a tool cannot eliminate areas within its boundary without compromising the ellipsoid integrity.

Major improvements in the analysis area have occurred during the last few years and tools have been developed that carry out statistical research in a spatial construct. These software include such examples as CrimeStat ${ }^{14}[13]$ now in version III. In addition, specialised tools have been developed by major software companies providing evidence that the commercial sector has seen ways to profit from "crime". Tools in the private and public domain include ESRI products (Crime Extension) ${ }^{15}$, MapInfo ${ }^{16}$ (Hotspot Mapping Extension ${ }^{17}$ ), Vertical Mapper ${ }^{18}$, and related products. In their study on Sheffield, Craglia et al [14] used SAGE ${ }^{19}$ and STAC $^{20}$ programmes. They used the software for the analysis of offence data, offender data as well as victim data. This has helped to develop a base for the study of crime through high-end software. Formosa [4] [5] developed a Malta-based Crime spatial information system for various analytical processes inclusive of journey to crime, poverty-offender analysis, hotspot mapping and the relative index of spatial crime.

The above topics identify GIS as a complex technology that has come to age at a crucial time for crime-analysis, allowing the analysis of large datasets through its crime-mapping technique and enabling dissemination through web-mapping technology.

\footnotetext{
${ }^{14}$ http://www.icpsr.umich.edu/CrimeStat/

${ }^{15} \mathrm{http} / / / \mathrm{www} . e s r i . c o m /$ industries/public-safety/law-enforcement/index.html

${ }^{16} \mathrm{http}: / /$ www.pbinsight.com/welcome/mapinfo/

${ }^{17} \mathrm{http}: / / \mathrm{www} . j \mathrm{ratcliffe}$. net/ware/index.htm

${ }^{18} \mathrm{http}: / / \mathrm{www}$.pbinsight.com/products/location-intelligence/applications/mappinganalytical/vertical-mapper/

${ }^{19} \mathrm{ftp} / / / \mathrm{ftp}$. shef.ac.uk/pub/uni/academic/D-H/g/sage/sagehtm/sage.htm

${ }^{20} \mathrm{http} / / / \mathrm{www}$. icjia.state.il.us/public/index.cfm?metasection=Data\&metapage=StacFacts
} 


\section{The Case for Maltese Web-Mapping}

The first thematic Maltese webmap was created in 2000 as based on the mapping of the Census of Population and Housing data $[15]^{21}$, which service was based on imagemapping and GIS-client technologies (Figure 2a). A year later (2001) the Malta Planning Authority launched its development planning mapserver ${ }^{22}$ which was based on MapInfo MapXSite ${ }^{23}$ that however lacked extensive querying capabilities (Figure 2b). The next web-map employing interactive technology was published by the National Statistics Office depicting the Census of $2005^{24}$, which employed geoclip ${ }^{25}$ and MapInfo applications. The next process initiated through the creation of environmental GI data layers such as habitats maps, which was carried out as part of a process to enhance spatial information for the general public and the research community in line with the EU/EEA dataflow requirements ${ }^{26}$. This process was achieved through the implementation of the Aarhus Convention that ensures that environmental information is disseminated for fre $\mathrm{e}^{27}$.

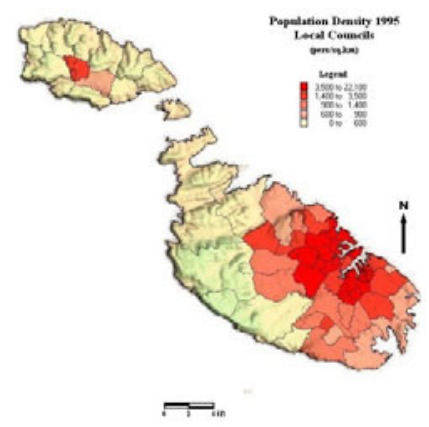

a)

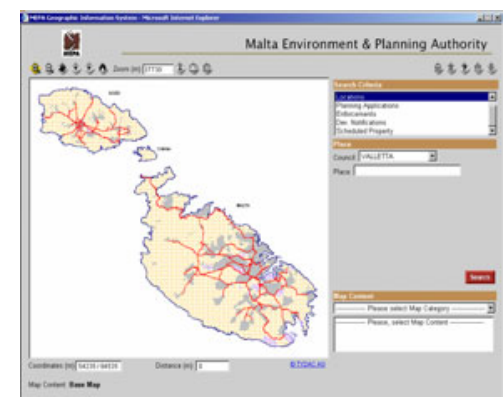

b)

Fig. 2. Thematic Maltese webmaps (a) Population Density Imagemap (b) MEPA Mapserver

\subsection{The Crime Spatial Outputs}

Based on the above benchmarking exercise, the different options available for the criminological study were identified and a local crime-mapping site developed. The technology employed is based on a MapInfo mbx programme developed by emc $3^{28}$,

\footnotetext{
${ }^{21} \mathrm{http}: / / \mathrm{www} \cdot \mathrm{mepa} . \mathrm{org} \cdot \mathrm{mt} / \mathrm{Census} / \mathrm{index} \cdot \mathrm{htm}$

${ }^{22} \mathrm{http}: / /$ www.mepa.org.mt/index.htm?links.htm\&1

${ }^{23} \mathrm{http}: / /$ www.pbinsight.com/

${ }^{24} \mathrm{http}: / /$ www.nso.gov.mt/site/page.aspx?pageid=570

${ }^{25} \mathrm{http}: / / \mathrm{www} \cdot$ geoclip.net

${ }^{26} \mathrm{http}: / /$ www.eea.europa.eu/

${ }^{27} \mathrm{http}: / /$ www.nesis.eu/index.php?option=com_wrapper\&view=wrapper\&Itemid=158

${ }^{28} \mathrm{http}: / /$ www.geoclip.net
} 
which uses Flash (swf) technology as its spatial carrier. Users can interact with the mapped data in a format they are already familiar with when browsing the internet. Simple help files are also available and guide the user on how to interact with the crime-map. Such a new approach is a major improvement from the early technologies of image-mapping and GIS-Client that required extensive downloading sessions. It is also an improvement as against a full map-server function that requires a remote and potentially heavy site [15]. Flash technology enables integration of the GI datasets and maps within a very small and simple flash file that can be conveyed easily over the web and even used on a standalone computer.

The prototype site created by the author encompasses a Web-GIS view with interaction on a number of variables such as police-reports crimes from 1998 to 2010, vehicle crime, serious and non-serious crime, amongst others. In terms of benchmarking, it is tagged with a 3-star rating for its pre-prepared structure that at the same time allows extensive user interaction such as personalised map creation and outputting. Figures 3a-3b depicts the Malta Crime Web-GIS created for this study (www.crimemalta.com).

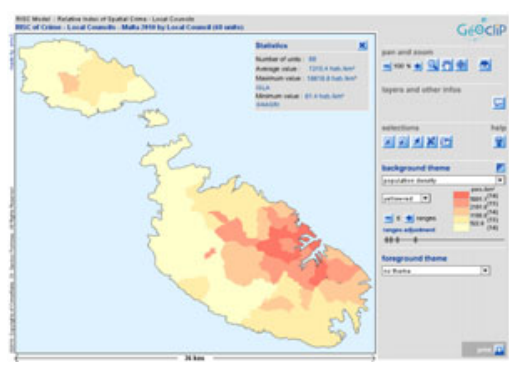

a)

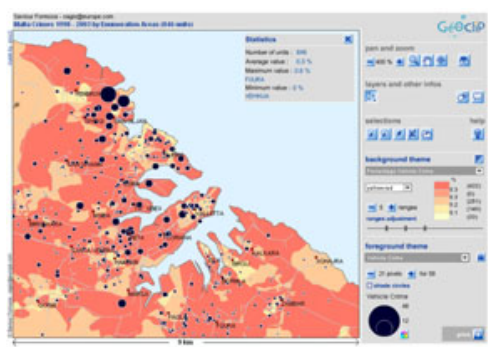

b)

Fig. 3. Malta Crime Web-GIS - www.crimemalta.com (a) choropleth (b) RISC map: choropleth and graduated

\subsection{The Plan4all Input: Hopes for Streamlining CRISOLA}

The CRISOLA outputs have had a significant input into the understanding of a social theme using a spatial construct, but the model itself needs to be structured towards a more realistic web-map structure. To date it is still too crude and requires streamlining towards the requirements of the INSPIRE Directive $[16]^{29}$. In effect, one project that has set the ball rolling for the next phase of spatial-social data interoperability for the CRISOLA outputs is the Plan4all project.

Plan4all is a European project running from May 2009 until October 2011 and cofinanced by the eContentplus programme of the European Commission. Plan4all focuses on interoperability and harmonisation of spatial planning data in Europe to

${ }^{29}$ The acronym INSPIRE refers to the Directive 2007/2/EC of the European parliament and the Council of 14 March 2007 with the aim to establish an Infrastructure for Spatial Information in the European Community. The directive entered into force on 15 May 2007 and will be fully implemented by member states in 2019 . 
support holistic spatial planning activities. All planning tasks and processes must be solved comprehensively with input from various sources inclusive the social themes. The diversity of data across the physical and social domains makes it necessary to make inputs interoperable because it allows the user to search data from different sources, view them, download them and use them with help of geoinformation technologies. Data harmonisation means that all member states use a common set of coordinate reference systems, data models, classification schemes, portrayal rules, etc. Interoperability is understood as providing access to spatial datasets through network services, independent from whether the existing dataset is actually changed (harmonised) or just transformed by a service for publication [17].

Why choose the Plan4all structure as a base for CRISOLA? The Plan4all metadata profile [18] states one of its aims at making spatial plans comprehensible and comparable. Spatial plans do not stand in a vacuum but require an understanding of the context they operate in, hence the social construct. As CRISOLA integrates social, criminological and landuse themes, the interoperable landuse pivot in both CRISOLA and Plan4all serves as a integrative function that will push the Malta model from its current 'quasi-static' phase to the next level. The issue stems on which structure one should use to move from a one-off output (the current crimemalta maps) to a dynamic webmap as is the planned Plan4all output using geoservers. For a social scientist this problem is inherent in its very structure; understanding all the available protocols and products is still a quagmire for GI experts let alone for the non-technic users. There are still too many languages and too many platforms that work in differential modes, which situation has created a veritable modern Tower of Babel. The problem that first Tower faced pivoted on the multiple-languages that the architects ended up speaking in and thus lost communicative processing, which fact killed the edifice. This time round too many protocols and too many disparate systems may yet kill the contemporary one. The need for technologists to understand the issues underlying data structures, datacycles and issues of access is paramount, especially when transferring this function to those related to the social disciplines.

The Plan4all project's focus on the definition of common procedures and methods for spatial planning data interoperability and harmonisation is something that CRISOLA aims to take up. CRISOLA can employ Plan4all metadata profile and object-oriented data models for data sharing via the Plan4all geoportal ${ }^{30}$ and guide them towards take-up within the social themes, themes that are not covered by the INSPIRE Annexes. The CRISOLA outputs can be brought into the Plan4all fold through the alignment of the already existent metadata, models and geoportal. Due to the fact that most of the data within the CRISOLA model falls within the landuse component, the direct linkage to the Plan4all is seen as the natural evolution for the model. The commonalities between CRISOLA and Plan4all lie in the fact that both profess a goal to support the exchange of compatible spatial planning data and to support the access to the data. Both have made access possible through options varying from simply viewing spatial data, up to even having the right to download it. Plan4all's concept to move away from 'insular information islands' towards 'information systems' and 'information infrastructures' that allow different kinds of user access to spatial data from various sources is seen as the springboard to use the

${ }^{30} \mathrm{http}: / / \mathrm{www}$. plan4all.eu/simplecms/?menuID=37\&action=article\&presenter=Article 
functionality for social thematic spatial dataset creation [19] [20]. In Malta social data is rarely created into spatial format and CRISOLA managed to link the landuse domain to the social domain and show that policy making can be done using such outputs. The next step is to take it to a full web-map format but within and established framework. The framework has been presented by INSPIRE and actuated by Plan4all.

This can be done for CRISOLA since the Plan4all geoportal presents geographic information from various sources in a unified way [21]. The Plan4all geoportal has two features that are basically map and catalogue. The catalogue client allows searching for metadata using OGC Catalogue Service for Web (CSW), something unheard of in the social domains. The map client allows viewing maps based on OGC Web Services and other formats (Google maps, KML, MapServer, GML). The basic functions include viewing web services (OGC WMS, WFS) selected by user from the catalogue or directly by address; saving user defined map projects on local hard drive a re-loading of this saved composition (OGC WMC); distance and area measurement; searching in the map; inserting user defined objects into the map, large format printing in PDF; showing legends, metadata and querying in the map. The Plan4all geoportal will enable users to search and view harmonised spatial planning data from the Plan4all partners with the aim to further extend the network with affiliated partners (Plan4all geoportal, http://www.plan4all.eu). CRISOLA will take the next step and attempt to extend that network to the social domains.

\section{The Next Steps for Data and Webmap Access in the Maltese Islands}

CRISOLA will not make it simply by employing the Plan4all methodology and operating around that structure's available datasets; it needs new data feeds to ensure that the dynamic social structures are backed by new and updated information. This is coming in the form of the next phase for webmapping and dissemination in Malta as currently being developed through an extensive Maltese ERDF project ${ }^{31}$ which entails the integration of physical, social and environmental data within a comprehensive Shared Environmental Information System ${ }^{32}$ structure as proposed by the EC. Having experienced instances of lack of data, a dearth of metadata on one hand and a relentless drive to take up new technologies, the Maltese scenario is ripe to integrate all the three CRISOLA issues (together with other thematic natural-social-physical environments through the employment of hi-end technology both insitu and remote. The resultant output will employ data-capture and scanning technologies that may yet make inroads in the social and planning operational fields. Through a planned complete terrestrial LIDAR scan combined with a bathymetric acoustic scan up to 1 nautical mile from the baseline coast and the inclusion of bathymetric LIDAR ensuring consistency in data acquisition across the two surveys, the baseline data will be created for the eventual overlaying of the thematic data. Combined with oblique imagery takes and in-situ data trawling, the end result should enable the production of a unique model of the islands for use across the scientific platforms.

\footnotetext{
${ }^{31} \mathrm{http}: / /$ www.mepa.org.mt/news-details?id=603

${ }^{32} \mathrm{http}: / /$ ec.europa.eu/environment/seis/
} 
The envisaged free dissemination of the data through Aarhus-compliance to the general public and the scientific community should enable the launching of integrated research across the spatial and social themes. Urban and environmental planners can undertake urban modeling scenario-building for strategic, regional and local areas, with the addon integration of social, economic and criminological issues leading to healthier and safer localities. In addition, the data will be integrated with impactanalysis of baseline studies for air, water, noise, soil and radiation themes and their impacts on high population/urban density Malta. It is envisaged that the project outputs will serve as a base for the creation of updated data for the crimemaps, which outputs will also be disseminated to other geoportals inclusive of the Plan4all geoportal in a harmonized format, thus ensuring homogeneity across the datasets. Thus the base landuse-related data requirement will be supplied through the ERDF project and the social data will be delivered through the Census 2011, which would require georeferencing and structuring in order to allow integration with the Plan4all requirements. The next step would require the integration of the crimemaps within the Plan4all mapserver which calls for integration of the original (pre-geoclip) spatial datasets within the metadata profile to ensure that the data fits within the geoportal.

As the CRISOLA landuse base data are the same used for the Plan4all geoportal harmonization should not offer major obstacles, especially since the base data layers created for the crimemaps adhered to the INSPIRE requirements. Malta's datasets originate from one datasource, the National Mapping Agency which has employed the JRC metadata editor since its launching phase, thus the crimedata fits within the requirements for that structure. In addition, whilst the current geoportals do not allow for user-interaction in terms of polygon creation at source, it is envisaged that such options be integrated in the project output to allow users to feed in into the online system.

Geographic data harmonization initiatives and projects such as Plan4all form a network of several thematic information systems - one being the Maltese Crime map - by providing harmonised, interoperable and accessible spatial data. The next phase for CRISOLA will see its integration of the Plan4all three main objectives that encompass the definition of standards for spatial planning data harmonisation according to INSPIRE, the implementation of the Plan4all geoportal that consists of harmonised spatial planning data that can be shared and third, to contribute to a European spatial data infrastructure. It is expected that the take-up by CRISOLA of the Plan4all data models and geoservers will be an important input to ensure that the initiation of social spatial datasets is set on a solid base.

\section{References}

1. Shaw, C.R., McKay, H.D.: Juvenile Delinquency and Urban Areas. University of Chicago Press, Illinois (1942)

2. Maguire, M., Morgan, R., Reiner, R.: The Oxford Handbook of Criminology, 2nd edn., p. 308. Oxford University Press, New York (1997) ISBN 0-19-876485-5

3. Entorf, H., Spengler, H.: Socio-economic and demographic factors of crime in Germany: Evidence from Panel Data of the German States. International Review of Law and Economics 20, 75-106 (2000) 
4. Formosa, S.: Spatial analysis of temporal criminality evolution: an environmental criminology study of crime in the Maltese Islands. Unpublished PhD Thesis. University of Huddersfield. United Kingdom (2007)

5. Formosa, S.: Maltese Criminological Landscapes: A Spatio-Temporal Case Where Physical and Social Worlds Meet. In: Buhmann, Pietsch, Kretzler (eds.) Peer Reviewed Proceedings of Digital Landscape Architecture 2010. Anhalt University of Applied Sciences. Wichmann Verlag, Heidelberg (2010) ISBN 978-3-87907-491-4

6. Chainey, S., Ratcliffe, J.: GIS and crime mapping (Mastering GIS: Technology, Applications \& Management). John Wiley \& Sons, Chichester (2005)

7. Schneider, R.H., Kitchen, T.: Crime Prevention and the Built Environment. Routledge, London (2007)

8. Felson, M., Clarke, R.V.: Opportunity Makes the Thief: Practical theory for crime prevention. Police Research Series, Paper 98. Home Office Policing and Reducing Crime Unit Research, Development and Statistics Directorate (1998) ISBN 1-84082-159-0

9. Ekblom, P.: The Conjunction of Criminal Opportunity: A framework for crime reduction toolkits. Policing and Reducing Crime Unit Research, Development and Statistics Directorate Home Office (2001)

10. Fritz, N.: The Growth of a Profession: A research means to a public safety end. In: Advances crime mapping techniques. Results of the First Invitational Advanced Crime Mapping Topics Symposium, June 2001. CMAP, Denver Colorado (2002)

11. Bruce, C.W.: Killing Crime at its Root. In Advances crime mapping techniques. In: Results of the First Invitational Advanced Crime Mapping Topics Symposium, June 2001. CMAP, Denver Colorado (2002)

12. Giddens, A.: The Constitution of Society: Outline of the Theory of Structuration. Polity Press, Cambridge (1984) ISBN 0-7456-0007-7pb

13. Levine, N.L.: CrimeStat: A Spatial Statistics Program for the Analysis of Crime Incident Locations (v 2.0). Ned Levine \& Associates, Houston, TX, and the National Institute of Justice, Washington, DC (2002)

14. Craglia, M., Haining, R., Wiles, P.: A Comparative Evaluation of Approaches to Urban Crime Pattern Analysis. Urban Studies 37(4), 711-729 (2000)

15. Formosa, S.: Coming of Age: Investigating The Conception of a Census Web-Mapping Service for the Maltese Islands. Unpublished MSc thesis Geographical Information Systems. University of Huddersfield, United Kingdom, http: / /www.mepa.org.mt/Census/index.htm (2000)

16. Official Journal of the European Union: Directive 2007/2/EC of the European Parliament and of the Council of 14 March 2007 establishing an Infrastructure for Spatial Information in the European Community (INSPIRE), L108, vol. 50 (April 25, 2007)

17. Plan4all Deliverable 2.3, Analysis of INSPIRE requirements (2009)

18. Kafka, S., Fiala, R.: Plan4all Deliverable 3.2.2, Plan4all metadata profile (2010)

19. Beyer, C., Wasserburger, W.: Plan4all Deliverable 2.2, Analysis of innovative challenges (2009)

20. Rubitzki, I., Vancutsem, D.: Plan4all Deliverable 2.1, Clusters of leading organisations in SDI for spatial planning (2009)

21. Plan4all geoportal, http: / /www.plan4all. eu (accessed in October 2010) 